\title{
A STUDY OF EXPLORING THE "BIG FIVE" AND TASK TECHNOLOGY FIT IN WEB-BASED DECISION SUPPORT SYSTEMS
}

\author{
Linwu Gu, Indiana University of Pennsylvania, Igu@iup.edu \\ Jianfeng Wang, Indiana University of Pennsylvania, jwang@iup.edu
}

\begin{abstract}
Although the "Big Five" model has been discussed a lot in behavioral fields, there has been little research on the impact of personality traits with regards to technology on web-based DSS decision. In this paper, we apply task technology fit theory to explore how Individual characteristics affect task technology fit and how task technology mediate between personal characteristics and decision-making. One of geographic information systems, Google Earth is used as geographic information system to find support for Internet users' web-based decision support systems. Data was gathered via a survey after an experiment of web-based decision making using Google Earth, which was completed by 192 undergraduate college students, and analysis was conducted utilizing structural equation modeling.
\end{abstract}

Keywords: Task Technology Fit (TTF), "Big Five" model, Individual characteristics, and Web-based DSS.

\section{INTRODUCTION}

The rapid growth of Internet has significantly increased the quantity of data available to Internet users, more and more people like to use visualization techniques to process and summarize high-volume data and information [20]. Previous studies have found the impact of geographic information system technology on decision performance [5]. As the Internet becomes the primary source of information, the use of geographic information systems technology becomes popular for web-based decision support systems. In the study of [7], the antecedents of task technology fit (TTF) are the interactions between task, technology, and individual characteristics. It is found [14] that the impact of individual characteristics on task technology fit is more important than the impact of others on task technology fit. In this paper, we focus on only one of the antecedents of task technology fit: individual characteristics. And the individual characteristic studied in the paper is the "Big Five" Model. The "Big Five" Model contains five individual personality traits such as extraversion, agreeableness, conscientiousness, neuroticism [15]. In this study, we set out to examine the task technology fit theory by considering the impact of individual characteristics. Two questions are asked in this study: first, "is there an effect of personal traits on task technology fit?', and, second, "how does task technology fit affect web-based information system decision?'

This paper is organized as follows. First we introduce personal traits of the "Big Five" and the theory of task technology fit. Second we review the theoretical basis from which the hypotheses are developed. Then we describe the research design and data analysis, respectively. Finally, we discuss the effect of "Big Five' on the web-based information system decision and provide a conclusion.

\section{THEORY FOUNDATION}

\section{Task Technology Fit}

The theory model of task technology fit (see in Figure 1) shows us the task, technology and individual characteristics have effects on task technology fit [7]. According to [17], the task technology fit explains that technology adoption is related to how well the technology fits the task requirements. Task technology fit has been measured in IT supported decision- making by [7], and [8].The importance of task technology fit is explained in processing information [23]. Different degree of the perception of task technology fit is associated with different outcomes [10]. In the study of [7], there are interactions between individual characteristics and task technology fit. Individual characteristic requires different kinds of technical functionality and it is associated with the functionalities of a technology. In a summary, individual characteristic is related to the positive individual performance through a good fit of technology. 


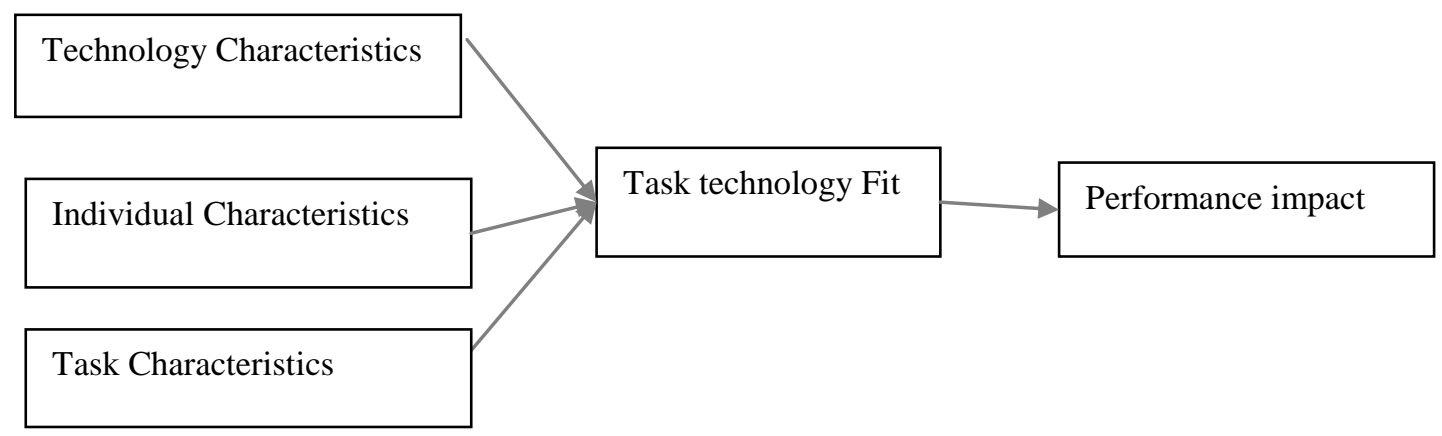

Figure 1. The theory model of TTF [7]

\section{"Big Five" Model}

Individual characteristics explain how individuals feel, think, and perform. And personal traits and behaviors can make a person unique [6]. Recent research about individual characteristics has focused on the "Big Five" model, which argues that most personalities can be grouped into 5 traits: 1 . extraversion; 2. neuroticism; 3. agreeableness; 4. conscientiousness; and 5. openness to experience. Extraversion is characterized by outgoing. Individuals high in Extraversion are more sociable, aggressive, and adapt to change faster [22] Agreeableness is related to trusting, concerned, simple and selfless [3]. People with high conscientiousness trait are described as being reliable, efficient and careful [1]. According to previous studies, openness personal trait is evaluated as independent and creative [1]. The relationship between neuroticism and anxiety in previous research is found in the study of [9].

\section{Technology}

Previous research found GIS was one of the most appropriate technologies to deal with high volume or complex data in decision making [10]. Google Earth is used as GIS program in our study which has three functions: mapping, searching, and sightseeing. Google Earth provides geographic information by combining satellite images, maps, and search. The information got from Google Earth can be print, or email, which is convenient to users. Functionalities of a technology are associated with individual performance in IT supported decision- making [7]. The theory of task technology fit is tested by using different technology such as GDSS [23]). In this paper, the technology we used is Google Earth, an example of graphic information system.

\section{RESEARCH AND HYPOTHESIS}

\section{Extroversion}

Extraversion can be defined as a trait that measures an Individual's approach to deal with their environment [15]. Individuals high in Extroversion prefer to focus on being social, adopt a leadership role, and independent [11]. Extraversion can be defined as social, fun looking, and affectionate [12]. It can be argued that individuals high in extraversion, who are enjoyable when interacting with others, will be more likely to make decisions online with respect to technology [22].

\section{Agreeableness}

Agreeableness is defined as trusting in and get along with others and by others [21]. Individuals in high degree of agreeableness are kind to others, more cooperative, have effective communication and willing to help other people [11], and [21]. Agreeableness is found to be one of predictors of interpersonal relations adjustment and performance [21].

\section{Conscientiousness}

Conscientiousness is characterized by being coherent, ordered, and informed [11]. Conscientious individuals tend to be well organized, careful, and self-disciplined [12]. Individuals scoring high in conscientiousness are prone to be more serious and cautious in making decisions and rely heavily on analyzing the available information in order to make a decision ([11], [22]) because they would be aware of potential risks, and less willing to take risks. Conscientiousness was identified as the strongest of the Big Five traits in its perceived influence on performance [16]. Individuals who are conscientious have been proved to have better perceptual- 
questioning skills that facilitate effective adaptation [13], and [22]

\section{Neuroticism}

A highly neurotic individual has a tendency to being anxious, nervous, depressed and blue [11]. Neuroticism is characterized by emotional instability, pessimism, and distrust. People high in neuroticism often think negatively and have less perceived control [22].

\section{Openness}

People in high openness prefer for diversity and are more independent, and imaginative [12]. People scoring high in this are more likely to make openminded decisions and are willing to accept new technology [22].

\section{Perceived task technology fit}

Task technology fit theory explains how technology impacts individual performance and how individual characteristics impact task technology fit. In the study of [7].Technology fit has been measured and explained by the user task domain of IT- supported decision making; and individual characteristic is one of the antecedents of task technology fit. Previous research finds the web-customers' perceptions can influence the use of web-based decision support systems [10].

Moreover, the perceived technology fit is proposed to impact performance in information processing and the degree of task technology fit is found to affect individual performance [10]. Previous research found decision-makers' perceived system effectiveness influenced the use of system [4]. The perception of task technology fit is measured as users' evaluation of task technology fit, and the constructs of perceived task technology fit are defined as perception of individuals about task technology fit in previous studies [7]. Furthermore, the effects of perceived task technology fit on performance vary from one person to another because of different personal backgrounds [10]. In the study of [14], individual characteristics were found to affect the perception of task technology fit.

\section{Decision making}

Decision making quality is defined as "individual's expectation of the quality of decision-making choices," [10]. Several previous studies explained decision quality outcome was expected to be right, correct, and precise. Decision-making quality could affect IT-performance relationship and the importance of developing quality decision support tools ([24], [19]). Moreover, technology or information system such as GSS could increase the quality of the decision-making process [18].

Perceived decision efficiency is defined as "the expectation of time spent and number of decision tasks completed," [10]. Decision -making with high efficiency is expected to use less time and is helpful [19].

According to the above literature reviews, we hypothesized as following (see in Figure 2):

$\mathrm{H}_{1}$ : Conscientiousness positively influences the perceived task technology.

$\mathrm{H}_{2}$ : Extraversion positively influences the perceived task technology.

$\mathrm{H}_{3}$ : Agreeableness positively influences the perceived task technology.

$\mathrm{H}_{4}$ : Neuroticism negatively influences the perceived task technology.

$\mathrm{H}_{5}$ : Openness positively influences the perceived task technology.

$\mathrm{H}_{6}$ : Perceived task technology positively influences perceived decision quality.

$\mathrm{H}_{7}$ : Perceived task technology positively influences perceived decision efficiency.

\section{RESEARCH AND METHODOLOGY}

\section{Variables}

The measurement items on the survey (see Appendix 1) were developed by adapting existing measures for prior research. The dependent variable is perceived decision efficiency and perceived decision quality. Both Perceived decision quality and perceived decision efficiency were adapted from [10]. The measures includes indicators of various aspects of decision outcomes, such as relevance, usability, reliability, time spent, and number of decisionmaking. The independent variables are individual characteristics from the "Big Five"model. All the measurement items for our independent variables were adapted from [1]). We used the 5 items for all our independent variables. There is one mediator: perceived task technology fit. The measure of perceived task technology is measured by [10]. All variables are measured by asking users their perceptions, and all instruments used 7 point Likertype scale, where $1=$ strongly disagree, and $7=$ strongly agree. 


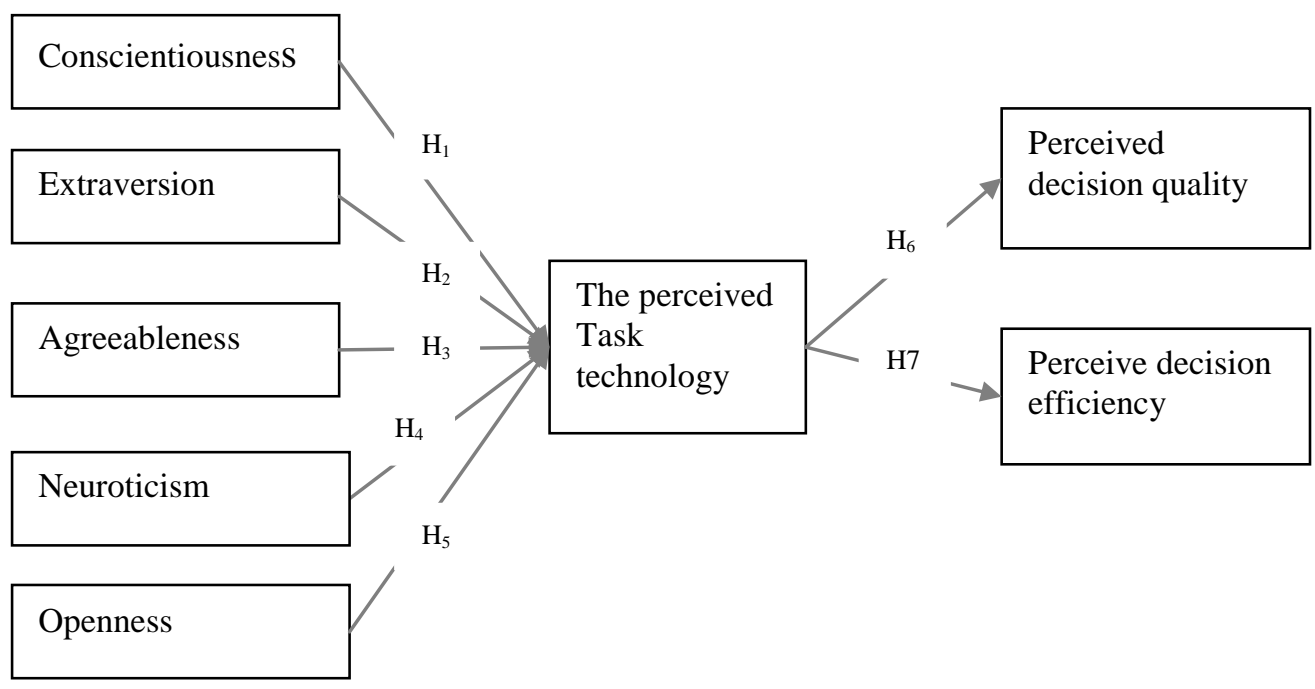

Figure 2. Individual characteristics of the"Big Five" model and Task-Technology in a Web Based Decision Support System

Table 1. Convergent Validity Test

\begin{tabular}{ccc} 
Constructs & $\begin{array}{c}\text { Average } \\
\text { variance }\end{array}$ & $\begin{array}{c}\text { Construct } \\
\text { reliability }\end{array}$ \\
\hline Extraversion & 0.61 & 0.728 \\
Neuroticism & 0.55 & 0.810 \\
Agreeableness & 0.53 & 0.860 \\
Conscientiousness & 0.54 & 0.842 \\
Openness & 0.62 & 0.911 \\
Perceived task technology & 0.55 & 0.892 \\
Perceived decision quality & 0.52 & 0.891 \\
Perceived decision efficiency & 0.67 & 0.920
\end{tabular}

\section{Subject and Procedure}

An experiment and a survey instrument containing measures (see in Appendix 1) were administered to business undergraduates at a large state university. Students in multiple section of an introductory course participated in the study. The experiment and the survey were done during class time. The class session is 90 minutes.

At the beginning of class, the subjects were introduced of how to use Google Earth as a real word decision making tool and utilize it as a simple geographic information system to make decision. Subjects were asked to do experiment by given tasks. For example, subjects were told to use Google Earth to find the existing Starbuck shops in a specific geographic area, then subjects were asked to make a decision for finding a best location using Google
Earth for a new Starbuck shop in the given area according to given information such as population density, access to roads, and transportation.

\section{DATA ANALYSIS AND RESULTS}

\section{Profiles of Experiments}

There were 192 subjects who did the experiments and post-session questionnaire. The mean age of the combined sample was 21.23 years, with 112 male and 80 female participants. There are 40 questions for all variables in the post-session questionnaire. Each variable has at least 4 questions (see in Appendix 1).

\section{Confirmatory Factor Analysis}

Confirmatory factor analysis is used to test the measurement model for the reliability and the validity 
and it is used to check whether the factor model is valid. The result of confirmatory factor analysis confirmed both convergent and discriminant validity (see in Table 2 and Table 3 ).

Convergent validity is evaluated based on composite reliabilities and average variances extracted [2]. From Table 2, the average variances extracted from constructs all exceeded 0.5 , and the composite reliability are all greater than 0.7 .

To assess discriminant validity, the square root of the average variance extracted is compared to the correlations of each pair of constructs. Discriminant validity is proved when the average variance extracted ( see in Table 3 the shaded numbers on the diagonal) is greater than the corresponding constructs correction [11].

\section{Structural Model Analysis}

Structural model was assessed by conducting a path analysis using LISREL software. We ran three separate structural models to examine significant relationships between our independent variables and mediator variable, as well as significant relationships between our mediator variable and our dependent variables. The independent variable should be tested how they are related to the dependent variable when the mediator is not tested, and that the relationship is reduced when the mediator is added to the structural model.

\section{Results}

The path diagram with the standardized results of the relationship of individual characteristics in the "Big five" model, perceived task technology, and perceived decision quality are shown in Figure 3. Results of the hypothesis testing are summarized in table 4. No significant relationship were found between extraversion and perceived task technology fit $(\beta=0.05, p=0.15)$, between neuroticism and perceived task technology fit $(\beta=0.03, p=0.45)$, between conscientiousness and perceived task technology fit ( $\beta=0.01, p=0.69$ ), and between perceived task technology fit and perceived decision quality ( $\beta=0.13, p=0.27$ ). Therefore, $\mathrm{H}_{1}, \mathrm{H}_{3}, \mathrm{H}_{4}, \mathrm{H}_{6}$ are not supported.

Both agreeableness $(\beta=0.23, p=0.07)$ and openness ( $\beta=0.15, p=0.00)$ have positive significant effects on perceived task technology. The significant relationship between perceived task technology and perceived decision efficiency was also found ( $\beta=$ $0.17, \mathrm{p}=0.034$ ). Therefore, $\mathrm{H} 2, \mathrm{H}_{5}$, and $\mathrm{H}_{7}$ were supported. However, only one mediating effect of perceived task technology fit between openness and perceived decision efficiency is identified significantly, because the relationship between openness and perceived decision efficiency was reduced when the mediator, the perceived task technology fit was added into the model.

Table 2. Discriminant Validity (E-Extraversion, A- Agreeableness, N-Neuroticism, C- Conscientiousness O-Openness, PTT- Perceived task technology, PDQ- Perceived decision quality, PDE- Perceived decision Quality)

\begin{tabular}{lllllllll} 
& $\mathbf{E}$ & $\mathbf{N}$ & $\mathbf{A}$ & $\mathbf{C}$ & $\mathbf{O}$ & PTT & PDQ & PDE \\
\hline $\mathbf{E}$ & 0.725 & & & & & & & \\
$\mathbf{N}$ & 0.451 & 0.713 & & & & & & \\
$\mathbf{A}$ & 0.032 & 0.081 & 0.726 & & & & & \\
$\mathbf{C}$ & 0.125 & 0.143 & 0.345 & 0.778 & & & & \\
$\mathbf{O}$ & & & & & & & & \\
& 0.023 & 0.376 & 0.074 & 0.062 & 0.722 & & & \\
$\mathbf{T T}$ & 0.152 & 0.156 & 0.164 & 0.011 & 0.321 & 0.754 & & \\
$\mathbf{P D Q}$ & 0.087 & 0.242 & 0.025 & 0.241 & 0.011 & 0.425 & 0.789 & \\
$\mathbf{P D E}$ & 0.033 & 0.09 & 0.065 & 0.156 & 0.077 & 0.051 & 0.012 & 0.763
\end{tabular}


Table 3. Hypothesis Testing Results

\begin{tabular}{lllll} 
Hypothesis & Relationship & $\boldsymbol{\beta}$ & P-value & Hypothesis Outcome \\
\hline $\mathrm{H}_{1}$ & Extraversion->perceived task technology & 0.05 & 0.15 & Not Supported \\
$\mathrm{H}_{2}$ & Agreeableness->perceived task technology & 0.23 & 0.02 & Supported \\
$\mathrm{H}_{3}$ & Conscientious ->perceived task technology & 0.01 & 0.69 & Not Supported \\
$\mathrm{H}_{4}$ & Neuroticism-> perceived task technology & -0.03 & 0.45 & Not Supported \\
$\mathrm{H}_{5}$ & Openness ->perceived task technology & 0.15 & 0.000 & Supported \\
$\mathrm{H}_{6}$ & Perceived task technology-> perceived decision & 0.13 & 0.27 & Not Supported \\
& quality & & & Supported
\end{tabular}

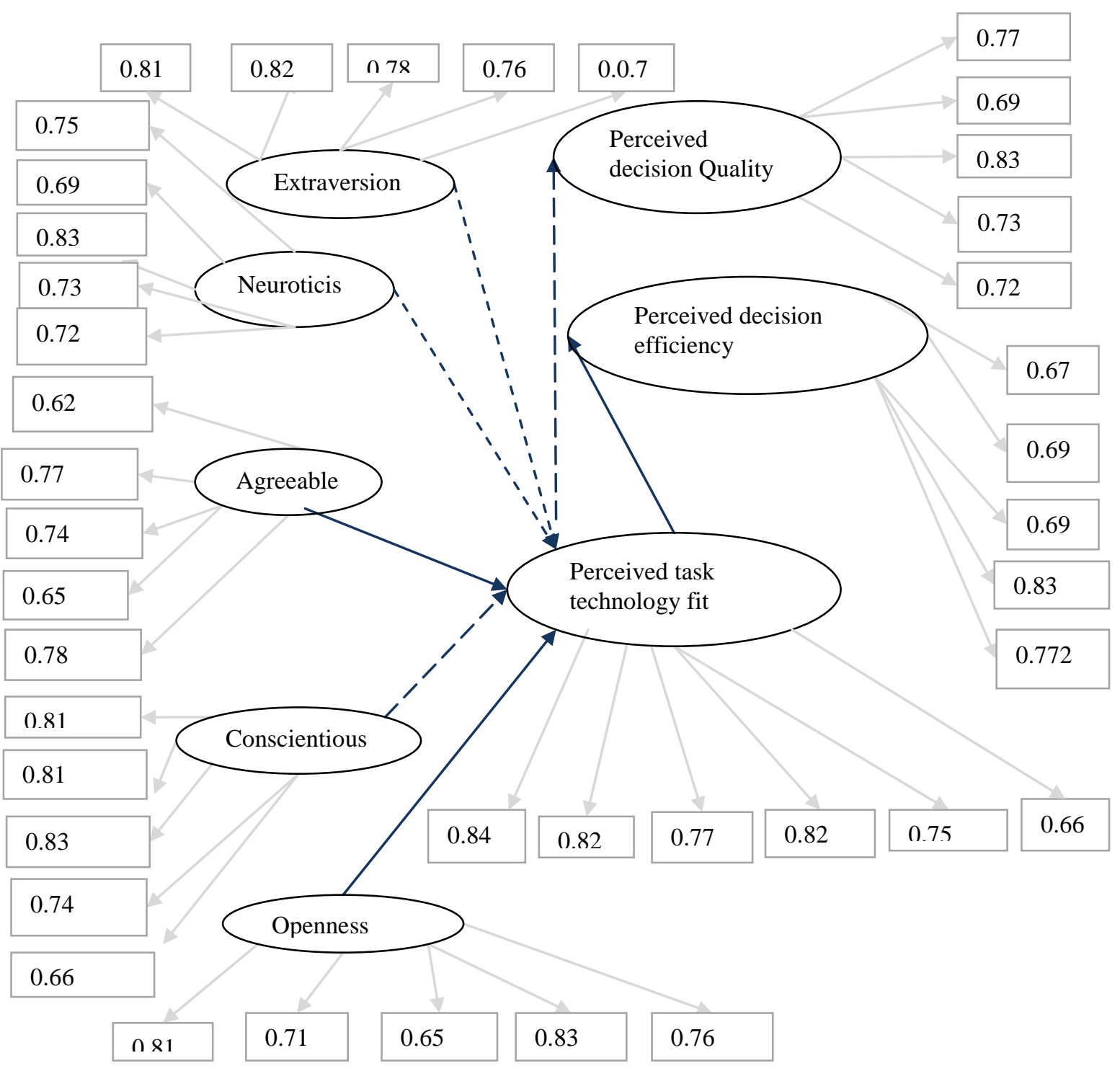


Figure 3. Path diagram with the standardized results of the effects of the individual characteristics in the "Big five" model and perceived task technology fit on perceived decision-making ( remarks: Factor loadings for each measured variable are within boxes)

\section{CONCLUSION}

We empirically validated some of the hypotheses based on the task technology fit theory. Our results show openness and agreeableness affect significantly on perceived task technology fit. Perceived task technology fit is proved to mediate between openness and perceived decision quality.

A better understanding of the effects of personal traits of web-based decision will help web-based decision support system designers to provide more personalized deigns for web-based decision systems. The present findings have implications for both researchers and practitioners. It would be interesting to know what individual characteristics really contribute to other web-based decision.

Our findings are subject to a number of limitations. First of all, all of our survey questions are perception questions. Our subjects are all undergraduate students which may affect the external validity of our study. So, it would be important to confirm our findings with a more representative sample of subjects.

\section{APPENDIX 1}

\section{Extraversion [1]}

I see myself as someone who

1. is talkative

2. is full of energy

3. generates a lot of enthusiasm

4. has an assertive personality

5. is outgoing, sociable

\section{Neuroticism [1]}

I see myself as someone who
1. is depressed, blue
2. can be tense
3. worries a lot
4. can be moody
5. gets nervous easily

\section{Agreeableness [1]}

I see myself as someone who

1. is helpful and unselfish with others

2. has a forgiving nature

3 . is generally trusting

4. is considerate and kind to almost everyone

5. likes to cooperate with others

\section{Conscientiousness [1]}

I see myself as someone who

1. does a thorough job

2. is a reliable worker

3. perseveres until the task is finished

4. does things efficiently

5. makes plans and follows through with them

Openness [1]

I see myself as someone who

1. is original, comes up with new ideas

2. is curious about many different things

3. has an active imagination

4. is inventive

5. likes to reflect, play with ideas

Perceived task-technology fit [10]

1. very inadequate vs. Very adequate

2. Not useful at all vs. Very useful

3. Very incompatible with the task vs. Very compatible with the tlask

4. Not helpful at all vs. Very helpful

5. Not sufficient at all vs. Very sufficient

6. In general, did not fit the task at all vs. Best fit the task

Perceived decision quality [10]

When using GIS, what is your confidence that your decision was

1. Accurate

2. Correct

3. Precise

4. Dependable

5. In general, I am confident that the quality of my decision was very low vs very high)

Perceived decision efficiency [10]

When using GIS, what is your confidence that your decision was

1. I arrived at a recommendation for the most appropriate decision (Slower vs. Faster)

2. I did (not to save time vs. To save time)

3. I was able to accomplish (fewer tasks vs. More tasks

4. In general, I was (inefficient vs. Efficient)

\section{REFERENCE}

1. Benet-Martinez, V and John, O.P. (1998). Big five in US Hispanic and Spanish samples, Journal of Personality and Social Psychology 75 (3), 729-749. 
2. Bock. G.. Zmud. R. W.. Kim. Y.. and Lee. J (2005). "Behavioral Intention Formation in Knowledge Sharing: Examining the Roles of Extrinsic Motivator, Social-Psychological Forces, and Organizational Climate, MIS Quarterly, (29:1),87-111

3. Costa, P. T., \& McCrae, R. M. (1992). Revised NEO Personality Inventory (NEO PI-R) and NEO Five-factor Inventory (NEO_FFI): Professional Manual, Psychological Assessment Resources, last accessed: 2 February 2000, at: http://www.sigmaassessmentsystems.com/ne opir.htm.

4. Davis, F.D. and Kottemann, J.E (1994). User Perceptions of Decision Support of Effectiveness: Two production Planning Experiments, Decision Sciences, 21(1), 5778

5. Dennis, A.R. and Carte, T.A. (1998). Using Geographical Information Systems for Decision Making: Extending Cognitive fit Theory to Map-Based presentations. Information Systems Research, 9(2), 194203

6. Dibb, S., Simkin, L. Pride, W.M., and Ferrell, O.C. (1994). Marketing Concepts and Strategies, Houghton Mifflin Company, Boston, MA.

7. Goodhue, D.L and Thompson, R.L, (1995). Task-Technology fit and Individual Performance. MIS Quarterly, 213-236.

8. Goodhue, D.L. (1998). Development and measurement Validity of a Task-Technology Fit Instrument for Uswer Evaluations of Information Systems. Decision Sciences, 29(12), 105-138

9. Harris. L. A and Dollinger, S.M. C. (2003). Individual Differences in Personality Traits and Anxiety About Aging". Personality and Individual Differences. 34(2), 187-194.

10. Jarupathirun, $\mathrm{S}$ and Zahedi, F. (2007).Exploring the Influence of Perceptual Factors in the Success of Web-based Spatial DS. Decision Support Systems, 43,933-951.

11. Korzaan, M and Boswell, K. (2008). The Influence of personality Traits and information Privacy Concerns On Behavioral Intentions. Journal of Computer Information Systems, Summer, 15-24

12. Lampe, J. (2004) Alternative personality measurements: commentary on accounting information systems research opportunities using personality type theory, Journal of Information Systems, 18(1), 21-34
13. Leiba-O'Sullivan, S. (1999). The distinction between stable and dynamic cross-cultural competencies: Implications for expatriate trainability. Journal of International Business Studies, 30, 709-725.

14. Marcolin, B.L, Compeau, D.R., and Munro, M.C. (2000). Assessing User Competence: Conceptualization and measurement, Information Systems Research, 11(1) , 37-60

15. McCrae. R. R. and Costa. P. T. (2003). Personality in Adulthood $2^{\text {nd }}$. The Guilford Press, New York. NY.

16. Ones, D. S., \& Viswesvaran, C. (1999). Relative importance of personality dimensions for expatriate selection: A policy capturing study. Human Performance, 12, 275-294.

17. Pagani, M. (2006)Determinants of Adoption of High Speed Data Services in the Business Market: Evidence for a Combined Technology Acceptance Model with Task Technology Fit Model, Information \& Management, 43847-860

18. Paul, Souren a, Haseman, William, and Ramamurthy K (2004). Collective memory support and cognitive-conflict group decision-making: an experimental investigation. Decision Support Systems 36, 261-281

19. Raghunathan, S. Impact of Information quality and Decision Maker Quality on Decision Quality: a Theoretical Model and Simulation Analysis (1999), Decision Support Systems, 26(4), 275-286

20. Romano, N.C., Donovan, C., Chen,H., and Nunamaker, J.F. " A methodology for analyzing web-based qualitative data," Journal of Management Information Systems 19(4), 2003, pp: 213-246

21. Shaffer, M. A and Harrison, D.A. (2006). You Can Take It With You: Individual Differences and Expatriate Effectiveness. Journal of Applied Psychology, 91( 1), 109125

22. Walczuch, R. and Lundgren, H. (2004). Psychological antecedents of institutionbased consumer Trust in e-retailing. Information \& Management, 4,159-177

23. Yoon, Y., Guimaraes, T., and O'Neal, Q.(1995). Exploring the Factors Associated with expert Systems Success. MIS Quarterly 1, 83-106.

24. Zigurs,I. \& Buckland, B.K.(1998). A theory of task/technology fit and group support systems effectiveness. MIS Quarterly, 2293), 313-334 